\title{
Editorial
}

\section{Who shall die?}

A British gynaecologist recently chose by ballot the patients who were to be admitted to the inadequate number of beds at his disposal. He had already selected those patients with gynaecologically urgent problems, and finding not much to chose medically between the rest, he obtained their consent to select by lot. He was subsequently criticised on radio by a medically qualified administrator for not using a better method of selection.

Well, what is a better method? The questionan extremely complex one-is raised in a more obviously serious context by two articles in this issue of the fournal. In the first Drs Parsons and Lock discuss the results of a survey they carried out among British nephrologists on their criteria for triage among patients with chronic renal failure. In the second Gavin H Mooney, the health economist, argues for the central importance of costbenefit analysis in the allocation of limited medical resources.

Parsons and Lock, disturbed by increasingly inadequate funds for dialysis and transplantation, asked twenty-five British nephrologists to reject ten out of forty realistically described patients, ticking their reasons for rejection from a check list under the categories of age, marital status, home facilities, underlying disease, and additional disease. All the nephrologists completed the questionnaire except for one who felt unable to accept any of the reasons suggested as valid grounds for rejection. Their responses make important reading. Interestingly, of the ten patients most generally rejected 'we found that at least six of them had been successfully treated by our own unit'; and not one of the patients was rejected by all the respondents.

Accepting for the time being that such choices must in practice be made, whereby some individuals are to be allocated life-saving resources while others with the same problem are to be refused them (microallocation, or triage) it may be worthwhile distinguishing different criteria upon which such choices might conceivably be made. Perhaps the one most commonly used in practice is that favoured by many of the respondents, notably the medical or technical criterion, whereby triage is based on the probability of successful medical outcome. In clear cases this criterion seems unproblematic; for example, other things being equal, a doctor faced with two patients needing blood transfusion and only enough blood for one would surely be not merely absurd but downright wicked to transfuse the patient with an incompatible blood group when the other's blood group matched that of the available blood. The criterion for proper choice here is quite clearly likelihood of medical success.

A second criterion for selection might be the candidates' value or disvalue to society; thus those respondents who rejected patients positive for australia antigen on grounds of the risk to other patients and staff of potentially lethal hepatitis were explicitly or implicitly using this social criterion, as were any respondents who wished to stop treatment on the grounds that resources are being drained by the heavily handicapped and homeless from other less demanding patients.' Similarly the traditional wartime criterion for triage (military importance) and the criterion of motherhood or parenthood of young children also fall into this category of social value.

A third criterion (properly class of criteria) might be the predicted quality of life or happiness or fulfilment of the competing candidates and a fourth might be their 'deserts,' based perhaps on their relative intrinsic goodness or worth. Other criteria, morally less defensible but perhaps sometimes used in practice, are the candidates' ability to pay for the treatment, or their ability to pull the right strings, or even the selecting doctor's personal preference. Finally there is selection on the basis of first come first served, which morally speaking is probably akin to rationing on the basis of lottery or random selection. The use of this last selection method may result from two quite different reasons; either the selectors may have been unable to decide upon a different method, or they may have positively chosen random allocation as morally the best method of allocating scarce life-saving resources.

If rational decisions are to be reached clearly a prerequisite is to decide which criteria for choice should be used. Unfortunately even the initially more attractive of the criteria mentioned have their problems. For instance the medical or technical criterion, while unexceptionable in clear cases and having the advantage that doctors are trained to use it, raises several important questions, semantic, epistemological and moral. Thus what do we mean by medical success; how do we know that medical success is more probable in one case rather than 
another; and is any degree of increased likelihood of medical success morally relevant: if so is it the only morally relevant criterion? Difficult as such questions are - and the other criteria are no simpler - we must surely attempt to answer them if decisions on who shall be denied life-saving resources have in practice to be made.

Parsons and Lock raise a second major question; who is to carry out the triage ? At present, as they state: 'physicians' professional expertise and position of trust is being used to translate economic and political decisions into selection of patients, without those presenting with renal disease, their relatives, or the public necessarily being aware of this process.' The answer depends, to some extent at least, on the answer to their previous questions about which criteria should be used for triage. Thus if it were decided that the medical criterion were sufficient, or alternatively that random allocation or a first come first served method were appropriate, then there seems less objection to doctors making the decisions; they have been trained to assess likely medical outcome and no special skill is required to use the other criteria. If on the other hand any of the morally evaluative criteria such as social value, quality of life, fulfilment, happiness, goodness or worth were to be accepted then it seems inappropriate for doctors to make such decisions and totally inappropriate for anyone to make them 'without those presenting with renal disease, their relatives or the public necessarily being aware of this process.'

Both of Parsons and Lock's important questions are moral and the second at least is also political; like so many of the fundamental problems in medical ethics they surely require thorough multidisciplinary appraisal.

\section{Why reject anyone?}

However, it may be argued that there is no need to be making these complex and sometimes agonising decisions at all. Renal failure is a finite problem and we simply need to allocate whatever resources are needed to treat anyone dying from it; indeed the Americans have gone some way along this road.

Before facing this argument it is worth asking whether it is intended to be generalisable to any finite demand for life saving medical resourcesto the totally implantable artificial heart for example, if this becomes a successful reality? If not, the questions of microallocation remain. And is the argument really intended to apply to anyone dying of renal failure, including the very old, those with other disease (including australia antigen!) and those who are already a great burden to society ? If not, again the problems of microallocation remain. However if the answers are affirmative to both questions then the problems of microallocation are replaced by those of macroallocation.
At first sight it may seem morally repugnant that anyone should be denied life-saving resources whilk money is spent by a Health Service on activities not intended to save life- on mental health fo example, or the hospice movement (though little enough is being spent on that). But as Moones points out, we do not in practice put an infinit value on saving life and the nearer we approache to doing so the more questionable it would become whether such life was worth saving, so greale would be the demand on our finite resources Saving or protecting life is only one of the many values which human beings have and in the distre bution of their total resources the amount allocated to saving lives must be at the expense of othen values such as welfare, education, defence, the arts and so on. Similarly even within the overafl category of health expenditure the saving of lives is only one value competing with others-with the treatment of non-fatal disease, with research, with. prevention, etc.

\section{Cost-benefit analysis}

Quantifying the advantages and disadvantages of different ways of allocating available resources essentially what the cost-benefit analysis extolleæ by Mooney is all about; and in so far as sucg quantification necessarily makes explicit what the various advantages and disadvantages of an allocation are assumed to be, it is a very useful aid to more rational, less haphazard choice. How? ever, cost-benefit analysis cannot tell us how to rank advantages and disadvantages; nor can make incommensurable benefits and harms coms mensurable; it would be a naive utilitarian indeed who believed that the pain and suffering experienced by many dialysis patients can somehow be weighe] on the same scale as either the cost of providing the dialysis or the benefit of saving their lives. Cost-benefit analysis can quantify the number of life-years per unit cost saved by one technique in comparison with another; it can quantify the monetary cost per life-year saved of differens techniques; on a different scale it can attempt to. quantify the pain and suffering of one techniques in comparison with another (morbidity figures provide one measure for such an analysis); it can attempt to quantify people's individual or institurs tional or political evaluations of different techniques or resource allocations: but what cost-benefop analysis cannot do is tell us which costs should be considered more or less acceptable, which benefits should be considered more or less desirable In the end we simply have to choose.

But while cost-benefit analysis cannot provide $\$$ sufficient basis for making such choices, in pro $\$$ viding relevant and specific data about alternative courses of action it is surely one of the necessars conditions for us to make them more rationally. 